\title{
SEX RATIOS IN SEXUALLY DIMORPHIC UMBELLIFERAE
}

\author{
DAVID G. LLOYD \\ Botany Department, University of Canterbury, Christchurch, New Zealand
}

Received 3.xi.72

\begin{abstract}
SUMMARY
Sex ratios in 35 inflorescence and plant counts of perennial, sexually dimorphic Umbelliferae vary from 0.96 to 87.33 times as many males as females. The ranges of ratios are similar in dioecious and gynodioecious populations.

In 10 populations in which both the inflorescences and plants were counted, the male/female ratios are approximately one in populations in which the plants produce only one inflorescence per year and increase as the average number of inflorescences increases.

The interpretation offered is that the sex ratio is approximately one until reproduction begins, and in subsequent years increasingly male-biased ratios develop because sexual reproduction utilises more of the available resources of females than of males. Following reproduction, male plants survive longer and grow more and so become predominant.

In dioecious Angiosperms generally, male-biased ratios are characteristic of long-lived repeatedly flowering species and may be partly due to differential post-reproductive growth.

It is postulated that male preponderance is not directly selected for, but is a secondary consequence of separate competition among males and among females during sexual reproduction. The seed set and fitness of total populations may actually decrease with the development of marked male preponderance.
\end{abstract}

\section{INTRODUGTION}

Although males and females are almost equally common in some sexually dimorphic plants and animals, sex ratios deviating from equality have been reported at various stages of the life cycle in other species. A number of theories have been proposed to account for the variety of sex ratios observed. The theories can be grouped into the following three categories on the basis of the postulated mode of selection:

1. The sex ratios are not directly selected, but are governed by the chromosomal sex-determination mechanism and any other factors, such as sex-differential mortality, which are selected for effects other than those on the sex ratio. In the absence of differential success of male- and femaledetermining gametes and of differential survival of the sexes, the sex determination mechanisms of most species automatically produce equal numbers of males and females. Unequal sex ratios may occur, for example, at all stages from the zygote to reproductive maturity in polyploid plants with more than one male genotype (Martin, 1967). Models of the effect of the quantity of seed produced by " hermaphrodites " of gynodioecious plants on the sex ratio (e.g. Lewis, 1941) assume that the sex ratio passively follows the relative reproductive output of the sexes.

2. The sex ratios maximise the reproductive success of individuals within a population. The best known hypothesis of this kind was proposed by Fisher (1930) and subsequently in greater detail by Kolman (1960) and 
Bodmer and Edwards (1960). They postulated that sex ratios are selected to equalise parental expenditure on male and female offspring. This hypothesis predicts equality of the sexes at the end of the period of parental expenditure, but not necessarily at earlier stages (if there is post-zygotic parental expenditure) or during reproduction.

3. The sex ratios are adjusted to maximise the fitness of populations rather than that of the individuals within a population. Several population parameters have been suggested as the object of selection. Kalmus and Smith (1960) proposed that both the opportunities for mating and the genetical variation available for natural selection are maximised when the sexes are equally common. Lewis (1942), Mulcahy (1967) and Kaplan (1972) have suggested that the sex ratio selected in plants maximises the total seed production of the population; the predicted sex ratio varies from equality to a marked excess of females, depending on the level of pollination. Wildish (1971) proposed that the sex ratio in Orchestia (Crustacea) populations regulates the reproductive potential of a population, and thus moves the density towards the optimal level. All these group selection hypotheses postulate that the target of selection is the sex ratio at reproduction.

Flowering plants have been the subject of relatively few sex ratio studies, although they have one considerable advantage over many animals, especially mammals. In Angiosperms, the period of parental expenditure, up to seed maturity, is relatively short in the life of the individual and is far removed from reproductive maturity. The intervening period is usually one of heavy mortality. There may therefore be considerable differences between the sex ratios of seeds and mature plants, providing evidence to distinguish between the various hypotheses. The sex ratios obtained in plants vary greatly (Lewis, 1942; Godley, 1964) and several factors, including gametic selection, sex-differential mortality, pollination and seed set levels and imperfect separation of the sexes have been invoked to explain the diverse ratios.

\section{SEX EXPRESSION IN DIMORPHIC UMBELLIFERAE}

The five genera Aciphylla, Anisotome, Scandia, Lignocarpa and Gingidia, together contain about 70 species and probably comprise a natural monophyletic group. They are all centred in or confined to the New Zealand region, where they represent one of the more spectacular adaptive radiations among the Angiosperms. The taxonomy of the group has been studied in a series of papers by Dawson, whose work to date is summarised in Dawson (1971).

Most species of Umbelliferae are sexually monomorphic, with only hermaphrodite flowers or with male as well as hermaphrodite flowers. The five New Zealand genera.are exceptional in the family in being sexually dimorphic or, occasionally, secondarily monomorphic following the loss of female plants. It is likely that sexual dimorphism evolved only once in a common ancestor of the five modern genera. Nevertheless, the sexual dimorphism in the group is not uniform. All species of the largest genera, Aciphylla and Anisotome, and one species of Lignocarpa are dioecious, with strictly unisexual male and female plants. Seven species of Gingidia, Lignocarpa and Scandia are gynodioecious, while $G$. trifoliolata and probably some populations of $G$. enysii lack females and are andromonoecious. 
The polleniferous plants of gynodioecious species bear a quantity of seed which varies greatly among the species and even among plants of one population. For example, in one population of G. montana the natural seed set on polleniferous plants varies from zero to 70 per cent. (Webb and Lloyd, unpublished data). Furthermore, preliminary experiments have shown that the presence or absence of seed on the polleniferous plants of at least some dioecious and gynodioecious species depends on environmental conditions. Hence the distinction between the two classes of sex expression is not absolute. Polleniferous plants of the gynodioecious populations, as well as those of the dioecious populations, are referred to below as males, following the convention adopted in Lloyd (1972). Female plants have never been seen to produce any pollen. In the New Zealand Umbelliferae, dioecy has probably evolved from gynodioecy by the gradual reduction of the seed set on males ( $c f$. Ross, 1970). Consequently, the sex ratios in the gynodioecious and dioecious species are considered together in the following results.

\section{Sex ratios}

Sex ratios were obtained in four genera (no counts of Scandia were made) by counting either the inflorescences or the plants in abundantly flowering populations. In all populations there was a minority of small, non-flowering

TABLE 1

Sex ratios (malelfemale) from inflorescence or plant counts of Aciphylla, Anistome, Lignocarpa and Gingidia populations

\begin{tabular}{|c|c|c|c|c|c|}
\hline \multirow[b]{2}{*}{ Species } & \multirow[b]{2}{*}{$\begin{array}{l}\text { Breeding } \\
\text { system }\end{array}$} & \multicolumn{2}{|c|}{ Inflorescence counts } & \multicolumn{2}{|c|}{ Plant counts } \\
\hline & & $\begin{array}{c}\text { Sample } \\
\text { size }\end{array}$ & $\begin{array}{c}\text { Ratio } \\
\delta / 9\end{array}$ & $\begin{array}{l}\text { Sample } \\
\text { size }\end{array}$ & $\begin{array}{c}\text { Ratio } \\
\delta / 9\end{array}$ \\
\hline Ac. monroi & Dioecious & 619 & $2 \cdot 87 * *$ & 一 & - \\
\hline Ac. aurea & Dioecious & 889 & 1.03 & - & - \\
\hline Ac. subflabellata & Dioecious & 276 & $4 \cdot 02 * *$ & - & - \\
\hline An. haastii & Dioecious & 312 & $4 \cdot 20 * *$ & - & - \\
\hline An. flexuosa & Dioecious & 267 & $6 \cdot 85 * *$ & - & - \\
\hline An. aromatica & Dioecious & - & - & 265 & $87 \cdot 33^{* *}$ \\
\hline An. aromatica & Dioecious & - & - & 243 & $4 \cdot 65 * *$ \\
\hline An. aromatica & Dioecious & 516 & $31 \cdot 25^{* *}$ & - & - \\
\hline An. aromatica & Dioecious & 472 & $10.51 * *$ & - & - \\
\hline An. aromatica & Dioecious & 330 & $10 \cdot 00^{* *}$ & - & - \\
\hline An. aromatica & Dioecious & 37 & $17 \cdot 50^{*}$ & - & - \\
\hline An filifolia & Dioecious & 280 & $13 \cdot 00^{*}$ & - & - \\
\hline An. filifolia & Dioecious & 146 & $4 \cdot 21 *$ & - & - \\
\hline L. diversifolia & Dioecious & - & - & 36 & $1 \cdot 40$ \\
\hline G. enysii var. anysii & Gynodioecious & 124 & $40 \cdot 33^{* *}$ & - & - \\
\hline G. trifoliolata & Andromonoecious & 411 & No females** & - & - \\
\hline G. trifoliolata & Andromonoecious & 117 & No females** & - & - \\
\hline
\end{tabular}

$*(P<0.05), * *(P<0.01)$; calculated on hypothesis of $1: 1$ sex ratio.

individuals which could not be sexed. The likely sex ratio in these plants, which are all or almost all pre-reproductive juveniles, is considered below. In those populations in which the plants are closely spaced and vegetative spread is considerable, individual plant limits are uncertain and only inflorescences were counted (table 1). In less dense populations observed before or after the flowering peak, only plant counts were recorded (table 1). 
In 10 populations, it was possible to take reliable counts of both kinds (table 2). The sex ratios are expressed as quotients, the number of males divided by the number of females.

Among the 37 counts of both kinds, there is a general preponderance of

TABLE 2

Sex ratios (male/female) of inflorescences, plant and inflorescences per plant in the same populations

\begin{tabular}{|c|c|c|c|c|c|c|c|}
\hline \multirow[b]{2}{*}{$\begin{array}{l}\text { Species and } \\
\text { collection }\end{array}$} & \multirow[b]{2}{*}{$\begin{array}{l}\text { Breeding } \\
\text { system }^{1}\end{array}$} & \multicolumn{2}{|c|}{ No. inflorescences } & \multicolumn{2}{|c|}{ No. plants } & \multicolumn{2}{|c|}{$\begin{array}{l}\text { No. inflorescences } \\
\text { per plant }\end{array}$} \\
\hline & & $\begin{array}{l}\text { Sample } \\
\text { size }\end{array}$ & $\begin{array}{c}\text { Ratio } \\
\delta / 9\end{array}$ & $\begin{array}{l}\text { Sample } \\
\text { size }\end{array}$ & $\begin{array}{c}\text { Ratio } \\
\delta / \%\end{array}$ & $\begin{array}{c}\text { Average }^{2} \\
\delta \text { and } q\end{array}$ & $\begin{array}{c}\text { Ratio } \\
\delta / \%\end{array}$ \\
\hline L. carnosula -1 & G & 102 & 1.04 & 98 & 0.96 & 1.04 & 1.08 \\
\hline Ac.s & $D$ & & & 96 & & & \\
\hline Ac. monroi & $D$ & 18 & $2 \cdot 7$ & 113 & $2 \cdot 42 * *$ & 1.60 & $1 \cdot 11$ \\
\hline Ac. & D & 4 & 1.7 & 234 & $1 \cdot 23$ & $1 \cdot 6$ & $1 \cdot 42$ \\
\hline L. carnosula -2 & G & 151 & $1 \cdot 85^{* *}$ & 80 & $1.67 *$ & 1.86 & $1 \cdot 11$ \\
\hline G. montana -1 & $C$ & 210 & $1 \cdot 5$ & 112 & 1.44 & 1.86 & 1.07 \\
\hline G. montana -2 & G & 749 & $3 \cdot 56 * *$ & 220 & $2 \cdot 24 * *$ & $3 \cdot 13$ & $1 \cdot 61$ \\
\hline G. decipiens & G & 588 & $4 \cdot 20^{* *}$ & 143 & $3 \cdot 61 * *$ & 3.94 & $1 \cdot 16$ \\
\hline G. enysii var. & & & & & & & \\
\hline An. flexuosa & $\mathrm{D}$ & $\begin{array}{r}203 \\
1392\end{array}$ & $15 \cdot 2 * *$ & $\begin{array}{r}40 \\
155\end{array}$ & $3.84 * *$ & $6 \cdot 65$ & 3.96 \\
\hline
\end{tabular}

${ }^{1} \mathrm{G}=$ gynodioecious, $\mathrm{D}=$ dioecious.

2 The populations are listed in increasing order of average number of inflorescences per plant in both sexes.

* $(\mathrm{P}<0.05)$,** $(\mathrm{P}<0.01)$; calculated on hypothesis of $1: 1$ sex ratio.

males, which is significant in 30 populations and often reaches extreme proportions. Only one count showed a slight, non-significant excess of females (48 male:50 female plants). The remaining ratios varied from 1.03 to 87.33 times as many males as females. In addition, in two inflorescence counts of G. trifoliolata, no females were observed (table 1). Dawson (1967) also found a lack of females in this species.

The range of ratios is similar in the two kinds of counts and in dioecious and gynodioecious species. Among the inflorescence counts, the 15 ratios of dioecious populations varied from 1.03 to $31 \cdot 25$, while the seven ratios of gynodioecious populations ranged from 1.04 to 40.33 (excluding the monomorphic G. trifoliolata). The geometric mean of all inflorescence ratios, excluding $G$. trifoliolata, is $4 \cdot 77$. When the $\chi^{2}$ tests from the 22 inflorescence counts are pooled by the relationship $\chi_{p}^{2}=(\Sigma \chi)^{2} / k_{i}$ (Bliss, 1967), the sex ratio is significantly different from $1.0\left(\chi_{p}^{2}=24230\right.$, with one d.f., $\left.P \ll 0.01\right)$. In the plant counts, the seven ratios of dioecious populations varied from $1 \cdot 23$ to $87 \cdot 33$, while the six ratios of gynodioecious populations varied from 0.96 to 3.61 . The geometric mean of all plant ratios, $2 \cdot 67$, is also significantly higher than $1.0\left(\chi_{p}^{2}=280, \mathrm{P} \ll 0.01\right)$.

There are clear differences between species in the sex ratios. For example, in all six counts on An. aromatica males were at least four times as frequent as females, whereas none of the four counts on $L$. carnosula reached a ratio as high as two. There is a tendency for the ratios to be higher in Anisotome than in the other genera but there is a wide overlap between genera.

Further analysis of the ratios is confined to the 10 populations in which both inflorescences and plants were counted. A third type of " ratio", that 
of the number of inflorescences per plant (male/female), was obtained for these populations by dividing the average number of inflorescences per plant in males by the average number in females of the same population. All 10 such ratios are above $1 \cdot 0$ (table 2), indicating that male plants generally have more inflorescences than female plants. The average ratio, 1.41 , is significantly higher than $1.0(t=2.78, \mathrm{P}<0.05$, tested on logarithms $)$.

The average number of inflorescences per plant in males and females combined provides a rough measure of the extent of vegetative reproduction and the size of the plants in the various populations. As the average size increases, there appears to be a general tendency for all three ratios to increase

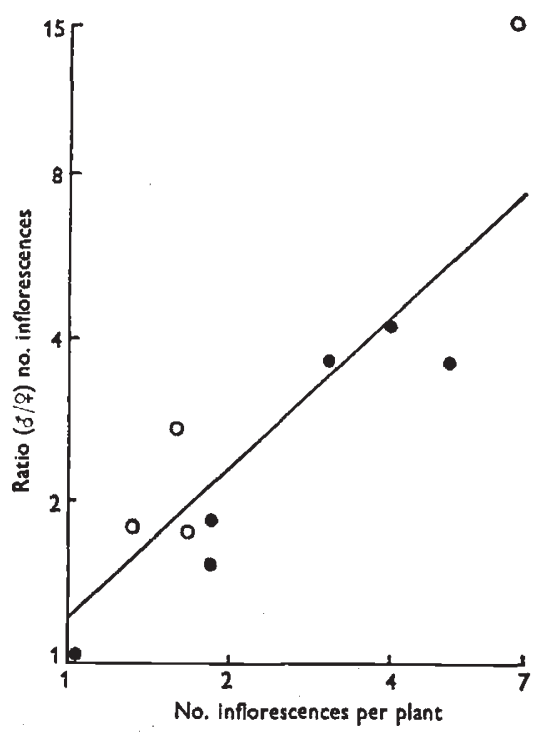

FIG. 1. - Regression of the logarithm $m_{10}$ of the ratio (male/female) of the number of inflorescences in a population on the logarithm $\mathrm{m}_{10}$ of the average number of inflorescences per plant, in 10 populations.

also (table 2). Model II regressions (Sokal and Rohlf, 1969) of the logarithms of each of the three ratios on the logarithms of the average number of inflorescences per plant were calculated. The regression of the inflorescence ratios on the number of inflorescences per plant (fig. 1) is significant at the 10 per cent level ( $b=0.94,90$ per cent confidence limits 0.23 and $1 \cdot 37)$. The estimated sex ratio in populations with only one inflorescence per plant (i.e. populations with no vegetative increase beyond that achieved prior to flowering), is 1.20 with 90 per cent confidence limits of 0.91 and 1.58 . Hence populations with plants of the smallest possible flowering size have approximately equal numbers of male and female inflorescences. As the plant size increases, the estimated inflorescence ratio increases to 6.47 in populations with an average of six inflorescences on each plant.

The regression of the plant ratios on the average number of inflorescences per plant (fig. 2) is also significant at the 10 per cent level $(b=0.58$, with 90 per cent confidence limits of 0.13 and 0.93 ). The estimated sex ratio in populations with only one inflorescence per plant is $1 \cdot 16$, with 90 per cent confidence limits of 0.96 and $1 \cdot 74$. So the plant ratio also does not differ 
significantly from equality when all plants produce only one inflorescence at a time. The estimated ratio rises to 3.26 for a population with an average of six inflorescences per plant.

The regression of the ratio of the number of inflorescences per plant (male/female) on the average number of inflorescences per plant is not significant $(P>0 \cdot 10)$. But with only 10 samples, the regression analysis is not very powerful. This ratio also may rise with increasing plant size, as the

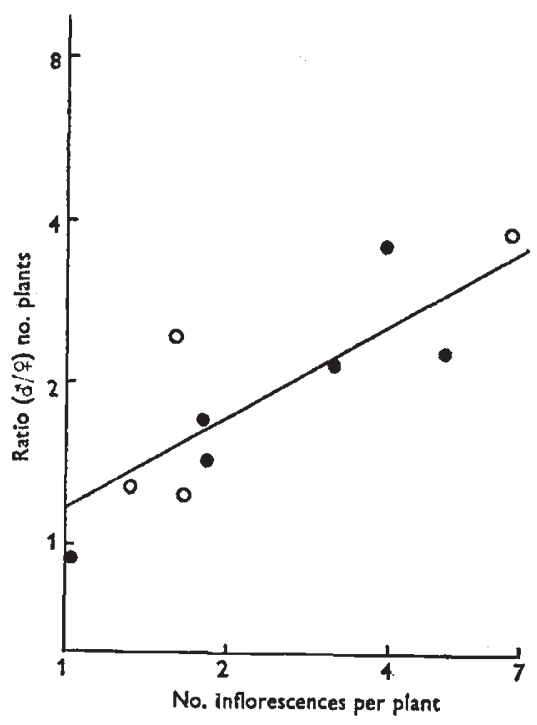

FIG. 2.-Regression of the logarithm ${ }_{10}$ of the ratio (male/female) of the number of plants on the $\operatorname{logarithm}_{10}$ of the average number of inflorescences per plant, in the same 10 populations. Open circles, dioecious populations; closed circles, gynodioecious populations.

three highest ratios all occur in populations with averages of more than three inflorescences per plant and the highest ratio occurs in the population with the largest number of inflorescences per plant.

Species of the five genera are slow-growing perennial herbs. I have observed the remnants of the previous year's inflorescences on flowering plants of all five genera. It is widely believed that the plants of all genera flower repeatedly over a number of years, but there are few accurate records. Dawson (personal communication) states that "at Otari (Gardens, Wellington) there are plants of Ac. squarrosa known to be 12 years old, which have flowered most years". The reproductive life of plants of some species probably spans several decades. The plants produce new leaves and stems after flowering. Hence the increases in the plant and inflorescence sex ratios with increasing numbers of inflorescences per plant may be interpreted as showing that the sex ratios progressively favour males in populations in which the plants have increasing number of flowering years with intervening vegetative growth. Conversely, the near equality of males and females in populations with only one inflorescence per plant suggests that in plants at the onset of flowering the two sexes are equally abundant and the deviant ratios develop only after reproductive maturity is reached. 


\section{Discussion AND CONCLUSIONs}

Previous sex counts of dioecious Angiosperm populations have shown a wide diversity of sex ratios. Most counts on 10 northern hemisphere genera (Löve, 1943; Smith, 1963, 1968; Zuk, 1963; Mulcahy, 1967; Putwain and Harper, 1972; Lewis, 1942 cites earlier counts) showed the sexes either near equality or with more numerous females, although one or more instances of male preponderance were observed in natural populations of Silene, Rumex and Populus species. In contrast Godley (1964), in counts of $16 \mathrm{New}$ Zealand and Chilean species belonging to 10 genera and families, listed a significant preponderance of males in 10 species, including one Gymnosperm. Significantly more females were found in only one species, Aciphylla aurea. (The reason for the discrepancy between the ratios for this species reported by Godley and the ratios recorded in this paper is not yet known.) Dawson (1967) reported that "hermaphrodites" (i.e. males) were more numerous than females in four gynodioecious Gingidia species. Shore (1969) recorded an excess of males in another dioecious New Zealand plant, Quintinia acutifolia.

Much of the diversity in the sex ratios of dioecious plants appears to be associated with differences in longevity between species and even within single species. The species with more numerous females are all herbaceous plants, either annuals like Mercurialis annua or perennials, such as Humulus japonicus. On the other hand, 13 of the 15 species previously reported with more numerous males in natural populations are long-lived woody perennials - mostly sizeable shrubs or trees. The other two species, Silene alba and Rumex acetosella, belong to genera with wide ranges in sex ratios which may be correlated with longevity.

In Rumex, $R$. hastatulus, a winter annual and $R$. thyrsiflorus, $R$. arifolius and $R$. acetosa, closely related perennials, have more numerous females (Correns, 1928; Smith, 1963; Zuk, 1963; Putwain and Harper, 1972), due in $R$. acetosa at least to gamete selection (Correns, loc. cit.). The perennial species $R$. paucifolius has a slight, non-significant excess of males (Smith, 1968). $R$. acetosella and its polyploid derivatives, $R$. angiocarpus and $R$. tenuifolius have approximate equality of the sexes in Europe (Löve, 1943; Putwain and Harper, 1972), but $R$. acetosella shows a significant excess of males (54 per cent) in counts of New Zealand populations (Harris, 1968). $R$. acetosella, with somewhat more numerous males than the other perennial species, spreads vegetatively more than does $R$. acetosa (Putwain and Harper, 1972) and has a weedy aggressiveness lacking in $R$. paucifolius (Smith, 1968). Moreover, Harris (1968) found that the preponderance of males was significant in relatively closed communities in which $R$. acetosella had been established for several years, but was not significant in larger counts on roadsides, recently grown pastures and weedy fallows, where establishment was relatively recent or impermanent.

An association between longevity and a preponderance of males may be present in Silene also. S. otites has a slight excess of males (62 per cent), whereas $S$. alba has a small deficit of males (44 per cent, Correns, 1928). Both species are short-lived perennial herbs, but according to Ghater and Walters (1964) and Coode and Cullen (1967), S. alba sometimes behaves as an annual.

The sex ratios in the Umbelliferae also follow the association between 
longevity, accompanied by vegetative spread, and a preponderance of males. As described above, males and females appear to be equally frequent until reproductive maturity. Then the males grow larger and survive longer than the females, becoming progressively predominant as flowering is repeated in subsequent years.

Several hypotheses are available to explain the preponderance of males in sexually dimorphic plants. The strongly male-biased sex ratios in dimorphic Umbelliferae and in other families cannot be easily explained by Fisher's (1930) hypotheses that sex ratios are adjusted to equalise parental expenditure on male and female offspring. A marked difference in parental expenditure on male and female seeds in a sexually dimorphic plant seems improbable in the relatively short period of parental expenditure during seed maturation. Moreover, the development of unequal sex ratios in the Umbelliferae and in Rumex acetosella appears predominantly, if not entirely, only in adult reproductive plants, long after parental expenditure has ceased. Differential production, germination or growth of male- and female-determining pollen and sex-differential seed germination or seeding growth were all listed by Godley (1964) as possible causes of male-biased sex ratios. These mechanisms also influence the sex ratio prior to sexual maturity and are unlikely to be the cause of male preponderance in the Umbelliferae and $R$. acetosella, at least.

A preponderance of males cannot be readily explained by any of the proposed group selection hypotheses, either. Most group selection hypotheses argue that the sex ratios are optimised at equality of the sexes (Kalmus and Smith, 1960) or when females predominate (e.g. Mulcahy, 1967; Kaplan, 1972) and hence do not apply to the present situation. Godley (1964) has suggested that " an excess of males may have arisen by selection to compensate for inefficiencies in pollination, in situations where seed production is limited by the availability of pollen and not by the number of ovules ". But when the males outnumber the females by several times, as in some of the Umbelliferae populations and in a proportion of the counts listed by Godley, the total seed capacity of the population is severely curtailed. Theoretical studies of the effect of the sex ratio on seed production in dioecious populations predict that the frequency of males will not exceed that of females, even when pollination is sparse (Kaplan, 1972; Lloyd, unpublished).

Faegri and van der Pijl (1966) suggested that the preponderance of males in Silene otites was an indication of transition from insect to wind pollination, but in view of the wide occurrence of male excesses in insect-pollinated plants (Godley, loc. cit., and the Umbelliferae considered here) this explanation is not generally tenable.

Harris (1968) proposed that the processes of flowering and fruiting in the females of Rumex acetosella caused a greater depletion of reserves than did flowering in the males. He postulated that the males are consequently better able to initiate and maintain growth in the post-flowering season and are thus more successful in vegetative competition and come to predominate in persistent populations. More recently, Putwain and Harper (1972) have shown that the males of $R$. acetosella do indeed allocate a higher proportion of their dry weight to vegetative reproduction than do females. They showed, however, that the adjustment of the sex ratio in $R$. acetosella is more complex than Harris postulated, since frequency-dependent growth of the sexes in experimental mixtures gives a relative advantage to the minority sex, tending 
to move deviant ratios towards equality. The two processes postulated by Harris and by Putwain and Harper may jointly control the sex ratio in this species. In the longer-established populations observed by Harris, the greater vegetative reproduction of the males apparently overrides, at least in part, the tendency towards equality.

A differential expenditure on male and female reproduction would also explain the much more deviant sex ratios observed in the dimorphic Umbelliferae. The natural history of these Umbelliferae suggests that the physiological cost of reproduction is higher in females than in males. The inflorescences are many-flowered and often large-up to 3 metres tall in Ac. scottthomsonii. After flowering, male inflorescences collapse and wither almost immediately, but female inflorescences remain alive and erect for several weeks while the seeds mature. The production of the many bulky seeds must entail a large expenditure of the females' energy resources. It would be expected, therefore, that female plants would grow less in the postreproductive season and would be more vulnerable to mortality factors. If this sex-differential performance was continued for a number of years, as the repeated flowering and apparent longevity of the plants indicate, increasingly male-preponderant sex ratios would result. The approximate equality of the sexes observed in the populations with the smallest plants and the increasing proportion and relative size of male plants with increasing plant size agree well with this hypothesis.

The explanation of male-biased ratios in terms of post-reproductive growth implies that these ratios are not selected for directly, but are a secondary, unavoidable consequence of the energy required for seed production. Natural selection may have indirectly produced predominantly male sex ratios in the following way. In a perennial species which reproduces repeatedly, a proportion of the resources available in any one year are used for reproduction and the remainder are invested in growth, defence and maintenance, which provide an opportunity for further reproduction in subsequent years (Murphy, 1968). During sexual reproduction in a dioecious species of this kind, males compete only with other males. Females compete separately with each other for their contributions to the gene pool of future generations. The fraction of resources invested in any one year in reproduction may, therefore, be selected at different optima in males and females. In general, we may expect that the seeds will require more physiological resources than the pollen necessary to fertilise them, and that consequently individual males invest proportionately more than females in vegetative growth. The reproductive success of a male relative to other males will be maximised even if this results in a reduction of the frequency of females and hence of the seed set and fitness of the total population. In those populations with heavily male-biased sex ratios, the extreme reduction in the total reproductive potential may well jeopardise the long-term survival of the populations, especially in such a physically heterogeneous and changeable environment as that in New Zealand during the adaptive radiation of the dimorphic Umbelliferae.

The postulated discrepancy between the sexes in optimal reproductive effort will exist only if individuals reproduce more than once; monocarpic species would be expected to maximise the reproductive effort of both sexes. The discrepancy may therefore explain, in part, the prevalence of sex ratios showing an excess of males in longer-lived Angiosperms. The differences 
between the sexes in reproductive effort depends, however, on other factors besides longevity and repeated flowering. The proportion of resources allocated to each episode of sexual reproduction, the size and number of seeds and the economy of pollination (the ratio of pollen grains to ovules) will all influence the discrepancy between the sexes in the allocation of resources and hence the development of male-biased sex ratios. Moreover, at least one other quite different mechanism causes unequal sex ratios in Angiosperm populations. It has been shown in a number of the species with more numerous females that female-determining pollen nuclei are more successful than male-determining pollen nuclei in fertilising ovules (reviewed in Godley, 1964 and Mulcahy, 1967). This process also contributes to the diversity of sex ratios in Angiosperms and might operate jointly with differential survival (and probably other factors) to control the sex ratio in some species.

Acknowledgments.-The sex ratios were counted while the author held a Miss E. L. Hellaby Indigenous Grasslands Research Fellowship. I am grateful to $\mathrm{Dr}$ J. W. Dawson and Dr M. D. Ross for comments on the manuscript.

\section{REFERENGES}

BLIss, C. 1. 1967. Statistics in Biology, Vol. 1, McGraw-Hill, New York.

BODMER, W. F., AND EDWARDs, A. W. F. 1960. Natural selection and the sex ratio. Ann. Hum. Genet., 24, 239-244.

Chater, A. O., AND Walters, s. M. 1964. Silene, in Flora Europaea, Vol. 1, 158-181, ed. Tutin, T. G. et al. Cambridge University Press, Cambridge.

COODE, M. J. E., AND Culden, J. 1967. Silene, in Flora of Turkey and the East Aegean Islands, Vol. 2, 179-242, ed. Davis, P. H. Edinburgh University Press, Edinburgh.

CORRENs, c. 1928. Bestimmung, Vererbung und Verteilung des Geschlechtes bei den höheren Pflanzen. Handb. Vererbungsw., 2, 1-138.

Dawson, J. W. 1967. The New Zealand species of Gingidium. New Zealand F. Bot., 5, 84-1 16. Dawson, J. W. 1971. Relationships of the New Zealand Umbelliferae. Bot. F. Linn. Soc., 64, Supplement 1, 43-62.

faEgri, K., AND VAN DeR PIJL, L. 1966. The Principles of Pollination Ecology. Pergamon Press Oxford.

FISHER, R. A. 1930. The Genetical Theory of Natural Selection. Oxford University Press, Oxford.

GODLEY, E. J. 1964. Breeding systems in New Zealand plants. 3. Sex ratios in some natural populations. New Zealand J. Bot., 2, 205-212.

HARRIs, w. 1968. Environmental effects on the sex ratio of Rumex acetosella L. Proc. New Zealand Ecol. Soc., 15, 51-54.

KALMUS, H., AND SMTth, c. A. B. 1960 . Evolutionary origin of sexual differentiation and the sex ratio. Nature, $186,1004-1006$.

KAPLAN, s. M. 1972. Seed production and sex ratio in anemophilous plants. Heredity, 28, 281-286.

xolman, w. 1960. The mechanism of natural selection for the sex ratio. Amer. Nat., 94, 373-377.

LEwIs, D. 1941. Male sterility in natural populations of hermaphrodite plants. New Phytol., $40,56-63$.

LEWIs, D. 1942. The evolution of sex in flowering plants. Cambr. Phil. Soc. Biol. Rev., 17, 46-67.

LLOYD, D. G. 1972. Breeding systems in Cotula L. (Compositae, Anthemideae). 1. The array of monoclinous and diclinous systems. New Phytol., 71, 1181-1194.

LövE, A. 1943. Cytogenetic studies on Rumex subgenus Acetosella. Hereditas, 30, 1-136.

MarTin, r. w. 1967. Sex ratio and sex determination in Dioscorea. J. Hered., 57, 95-99.

MULCAHY, D. L. 1967. Optimal sex ratio in Silene alba. Heredity, 22, 411-423.

MURPHY, Q. I. 1968. Pattern in life history and the environment. Amer. Nat., 102, 391-404. 
PUTWAIN, P. D., AND HARPER, J. L. 1972. Studies in the dynamics of plant populations. V. Mechanisms governing the sex ratio in Rumex acetosa and $R$, acetosella. 7. Ecol., 60, 113-129.

Ross, M. D. 1970. Evolution of dioecy from gynodioecy. Evolution, 24, 827-828.

SHORE, B. F. 1969. Dioecism in New Zealand Escalloniaceae. New Zealand 7. Bot., 7, 113 124.

sмrтн, в. w. 1963. The mechanism of sex determination in Rumex hastatulus. Genetics, 48, $1265-1288$.

smrrt, B. w. 1968. Cytogeography and cytotaxonomic relationships of Rumex paucifolius. Amer. 7. Bot., 55, 673-683.

SOKAL, R. R., AND ROHL, p. J. 1969. Biometry. Freeman, New York.

wILDISH, D. J. 1971. Adaptive significance of a biased sex ratio in Orchestia. Nature, 233, 54-55.

żuK, J. 1963. An investigation on polyploidy and sex determination within the genus Rumex. Acta Soc. Bot. Pol., 32, 5-67. 
